\title{
Shape-controlled synthesis of silver particles by surfactant self-assembly under ultrasound radiation
}

\author{
Jafar Moghimi-Rad • Taghi Dallali Isfahani • \\ Iraj Hadi · Sousan Ghalamdaran • \\ Jamshid Sabbaghzadeh • Mohammad Sharif
}

Received: 18 January 2011/ Accepted: 18 March 2011/Published online: 20 April 2011

(C) The Author(s) 2011. This article is published with open access at Springerlink.com

\begin{abstract}
Several methods have been offered for silver nanoparticles production. A new method has been developed including shape-controlled synthesis of silver nanoparticles in different shapes. Dendrite, cubic, spherical and porous structures were formed by self-arrangement of the surfactant as a template under ultrasound radiation. In order to produce silver particles, ascorbic acid has been used to reduce an aqueous solution of silver nitrate in the presence of dodecylbenzenesulfonic acid sodium salt, poly (vinyl pyrrolidinone), and a mixture of organic and aqueous solutions. Scanning electron microscopy and transmission electron microscopy analysis revealed that the morphology and the size of produced particles were influenced by the type of capping agent, presence of ultrasound radiation, and crystallization time. In order to measure the surface roughness of dendrite and porous particles, an optical reflectometer was used. Surfactant molecules in an aqueous solution can aggregate in different shapes depending on temperature, ionic property of solution, time, and aprotic solvent content.
\end{abstract}

Keywords Silver particles · Self-assembly · Dendrite . Nanoparticles · Ultrasound radiation .

Shape-controlled synthesis

J. Moghimi-Rad · T. D. Isfahani · I. Hadi ·

S. Ghalamdaran $(\varangle) \cdot$ J. Sabbaghzadeh · M. Sharif Iranian National Center for Laser Science and Technology, P.O. Box 14665-576, No. 8, 7th Mahestan Street, Phase 1, Shahrak-e-Qods, Tehran, Iran

e-mail: Sousan.ghalam@yahoo.com

\section{Introduction}

In recent years, much attention has been paid to metallic nanoparticles due to their potential in catalytic, biologic, and electronic applications (Murphy 2002; Huang and Murray 2001; Kamat 2002; Zhang 2003; Rosi and Mirkin 2005; Daniel and Astruc 2004; Morones et al. 2005; Elechiguerra et al. 2005). Their novel optical, thermal, chemical and physical properties are because of higher surface energy of nanoparticles compared to the bulk solid and short mean free path of an electron in a metal (10-100 $\mathrm{nm}$ for many metals at room temperature).

Among various metallic particles, silver nanoparticles have attracted considerable attention due to their superior thermal and electrical conductivity (Li et al. 2010; Moon et al. 2006). Nanoparticle preparation has been developed through various methods including ultraviolet irradiation photo reduction (Zhou et al. 1999), sonoelectrochemical synthesis of nanoparticles (Saez and Mason 2009), microwave-assisted synthesis (Mallikarjuna and Varma 2007), electrocrystallization (Murashova et al. 2003), electroless metal deposition (Qiu et al. 2005), photo reduction (Yonezawa et al. 2005), laser ablation (Brito-Silva et al. 2010; Tsuji et al. 2008; Jiménez et al. 2007). In addition, several chemical and biological procedures have been offered involving: polyol (Sun et al. 2003; Zhu and $\mathrm{Hu}$ 2004; Gautam et al. 2007; Wiley et al. 2005), hydrothermal (Zhang et al. 2006), template (Adhyapak et al. 2004; Sun et al. 2005; Hong et al. 2001), surfactant self-assembly (Pileni 2003) as chemical methods. Culture supernatant of bacteria with microwave irradiation (Saifoddin et al. 2009), and production of metal nanoparticles by microbes (Kannan Badri and Natarajan 2010) are some examples of biological synthesis of nanoparticles. Some researchers have considered the effect of templates. Static, hard and soft templates 
have been, respectively, used to enhance the growth rate of one crystallographic face over another (Cho 1999; Zhao et al. 2004; Hu et al. 1999), anisotropic growth (Huang et al. 2000) and synthesis of different shape of particles (Pileni 2003; Suber et al. 2005; Ding et al. 2008; Wei 2006; Eastoe et al. 2006). Within all these methods, surfactant selfassembly has been widely reported because of its superior ability in controlling the size (Jana et al. 2001; Kovalenco et al. 2007) and morphology (Jana et al. 2001; Kovalenco et al. 2007; Wang et al. 2002; Johnson et al. 2002; Liu et al. 2009; Nishino and Kanno 2008) of nanoparticles. In the present work, self-arrangement property of the surfactant as a template has been investigated to produce different shapes of particles such as cubic, porous micro-rod, sphere and dendrite forms under ultrasound radiation.

Following our previous studies on the effect of ultrasound radiation on size and size distribution of copper particles (Moghimi-Rad et al. 2010), simple one-step procedure have been developed to synthesize anisotropic silver nanoparticles. Anionic surfactants and neutral polymers in water/oil solution have been applied as soft templates to synthesize anisotropic silver nanoparticles. Dodecylbenzenesulfonic acid sodium salt (SDBS) and poly (vinyl pyrrolidinone) (PVP) have been applied as a surfactant and capping agent, respectively. We have studied the effects of surfactant, polymer molecules and both of them on the size and morphology of particles in different crystallization times. Dendrite and porous micro-rod were the results of silver reduction inside of surfactant self-assembled structures in the presence of ultrasound radiation.

\section{Materials and methods}

Materials and synthesis

All reagents used in this work were analytical grade, including silver nitrate (AgNO3, $M_{\mathrm{w}}=170 \mathrm{~g} / \mathrm{mol}$, Merck), ascorbic acid $\left(\mathrm{C}_{6} \mathrm{H}_{8} \mathrm{O}_{6}, M_{\mathrm{w}}=176.12 \mathrm{~g} / \mathrm{mol}, 99 \%\right.$, Aldrich), dodecylbenzenesulfonic acid sodium salt (SDBS) $\left(\mathrm{C}_{18} \mathrm{H}_{29} \mathrm{NaO}_{3} \mathrm{~S}, M_{\mathrm{w}}=348.48\right.$, Fluka), poly (vinyl pyrrolidinone) (PVP 6000) $\left[\left(\mathrm{C}_{6} \mathrm{H}_{9} \mathrm{NO}\right)_{n}\right.$, Merck], and $n$-heptanes $\left(\mathrm{C}_{7} \mathrm{H}_{6}, M_{\mathrm{w}}=100.21 \mathrm{~g} / \mathrm{mol}\right.$, Merck $)$.

A typical synthesis involves the preparation of a solution consisting of $40 \mathrm{~mL}$ deionized water, $0.68 \mathrm{~g}$ (2 mmol) SDBS, $0.22 \mathrm{~g}(2 \mathrm{mmol})$ PVP, and $0.36 \mathrm{~g}(2 \mathrm{mmol})$ ascorbic acid in various concentrations (Tables 1, 2, 3). In order to prepare the first solution, the mentioned materials had been homogenized, then the second solution consisting of $20 \mathrm{~mL}$ deionized water, and $0.34 \mathrm{~g}$ (2 mmol) $\mathrm{AgNO}_{3}$ was added to the first one under ultrasound radiation.

To prepare various morphologies of silver particles, the final solution has been treated in several distinctive precipitation pathways (Tables $1,2,3) .30 \mathrm{ml}$ of $n$-heptanes was added to the final solution under sonication (Probe ultrasonic Sonifer 450, 50-60 Hz), which resulted in fast rearrangement of surfactants. This reassembly of the surfactant led to the formation of porous rod and dendrite structures precipitating instantly. Residue of this solution has been centrifuged after two different crystallization times. Centrifuging after $30 \mathrm{~min}$ and 5 days led to spherical and cubic nanoparticles formation, respectively. Recovered silver particles from the solution were subsequently washed with distilled water and dried in the oven. Typically, during titration of the silver nitrate solution, ascorbic acid reduces the silver ions to the metallic forms by an electron transfer reaction. Scanning electron microscopy, transmission electron microscopy and optical reflectometer were employed to reveal the morphology, size and surface roughness of the prepared silver particles, respectively.

\section{Characterization of silver nanoparticles}

In addition to the particle size and size distribution, phase composition and crystallinity of the synthesized silver particles were investigated by using an X-ray diffractometer. The phase analysis was conducted on the silver particles (sample \#1). The X-ray diffraction patterns correspond to silver with a crystalline face centered-cubic (fcc) structure as shown in Fig. 1. The prepared particles were determined to be pure Ag without any impurity.

\section{Results and discussion}

Basic chemical reaction

Typically, during titration of the silver nitrate solution, ascorbic acid converts to the oxide form through a radical reaction and reduce the silver ion to the metallic form.

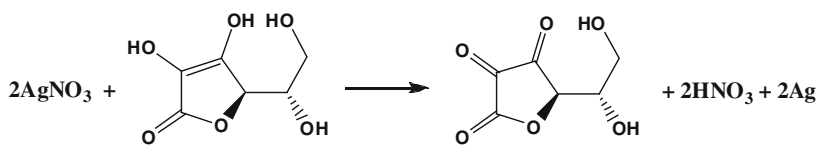

Effect of capping agent on the particles size under ultrasonic radiation

Effect of PVP as a capping agent has been studied under ultrasound radiation. Figure 2 shows SEM images of synthesized particles with and without presence of PVP (Table 1). Results indicated that presence of PVP could remarkably decrease the average size of particles, which is 
Table 1 Reactions with and without PVP as a protecting agent

\begin{tabular}{lllll}
\hline Sample ID & Protecting agent & Protecting agent $(\mathrm{mmol})$ & Ultrasound radiation & Solvent \\
\hline$\# 1$ & - & - & Yes & Water \\
$\# 2$ & PVP & 2 & Yes & Water \\
\hline
\end{tabular}

Table 2 SDBS as a protecting agent with and without $n$-heptanes solvent

\begin{tabular}{llllll}
\hline Sample ID & Protecting agent & Protecting agent $(\mathrm{mmol})$ & Ultrasound radiation & Solvent & Separation \\
\hline$\# 3$ & SDBS & 4 & Yes & Water & Self-precipitation \\
$\# 4$ & SDBS & 4 & Yes & Water and $n$-heptanes & Centrifuge \\
\hline
\end{tabular}

Table 3 SDBS and PVP as protecting agents in different precipitation pathways

\begin{tabular}{llllll}
\hline Sample ID & Protecting agent & Protecting agent $(\mathrm{mmol})$ & Ultrasound radiation & Solvent & Separation pathway \\
\hline$\# 5$ & SDBS and PVP & 4 and 2 & Yes & Water and $n$-heptanes & Self-precipitation \\
$\# 6$ & SDBS and PVP & 4 and 2 & Yes & Water and $n$-heptanes & Centrifuge after 30 min \\
$\# 7$ & SDBS and PVP & 4 and 2 & Yes & Water and $n$-heptanes & Centrifuge after 5 days \\
\hline
\end{tabular}

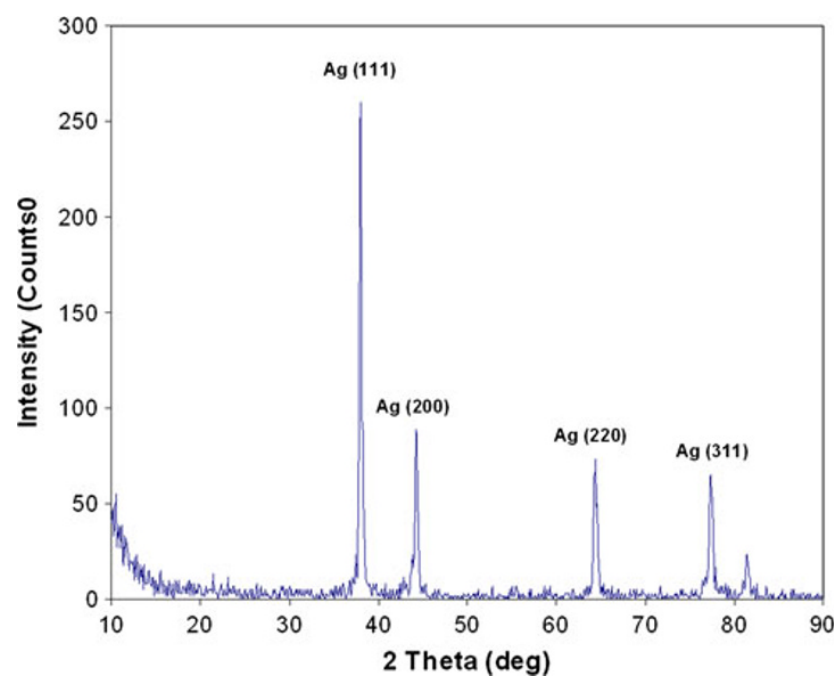

Fig. 1 X-ray diffraction of synthesized silver particles (sample \#1)

in agreement with Dan Min et al. report (Dan Min et al. 2008). In our previous work (Moghimi-Rad et al. 2010), it has been shown that the ethylene glycol (EG) as a capping agent could influence diversely on the size and size distribution of synthesized copper particles. This contradiction in observation can be explained through the different interaction of protecting agents and ions. As it was described, copper ion-EG complex retards the reduction process and consequently increases the particles size (Moghimi-Rad et al. 2010). In the present work, due to the reduction ability of both PVP molecules (Dan Min et al. 2008; Wu et al. 2010; Kan et al. 2005) and ultrasound radiation (Liu et al. 2009; Solano Ruiz et al. 2010; Talebi et al. 2010), the reduction reaction of silver ions can be facilitated. The presence of PVP not only facilitates the production of silver atoms, but also prevents individual colloidal particles from coalescing with each other (Ahmadi et al. 1996), which results in finer particles with narrower standard deviation.

Effect of surfactant on the particles morphology and size under ultrasonic radiation

Silver particles have been produced in the presence of SDBS in order to investigate the effect of surfactant selfassembly on the size and shape of particles under ultrasound radiation. Results show that applying different combinations of solvents including water (Fig. 3a) and water $/ n$-heptanes (Fig. $3 b$ ) could influence surfactant selfassembly, leading to different morphology and size of particles. In static condition, presence of hydrophobic solvent affects the surfactant self-arrangement and results in porous microstructures (sample \#3). Following the attachment of positive silver ions to the micelles surface, repulsive force will be reduced within anionic heads of surfactant molecules, leading to an increase in packing parameter (Zhang et al. 2004), so large porous silver particle formation is the result of an expansion in spherical micelles (Fig. 3a). Dumbbell-like structures have been produced by adding $n$-heptanes during the sonication. Vinson et al. (1991) showed that addition of $n$-heptanes could increase the packing parameter, so that reverse micellar structures will form. On the other hand, Wang et al. (2009) reported the effect of dodecanol on the selfassembly of SDS to form dumbbell-like structures of $\mathrm{CuO}$. Thus, it can be concluded that the presence of $n$-heptanes 
Fig. 2 SEM images of synthesized silver particles. a Without using any capping agent (sample \#1); $\mathbf{b}$ in the presence of $2 \mathrm{mmol}$ PVP (sample \#2)
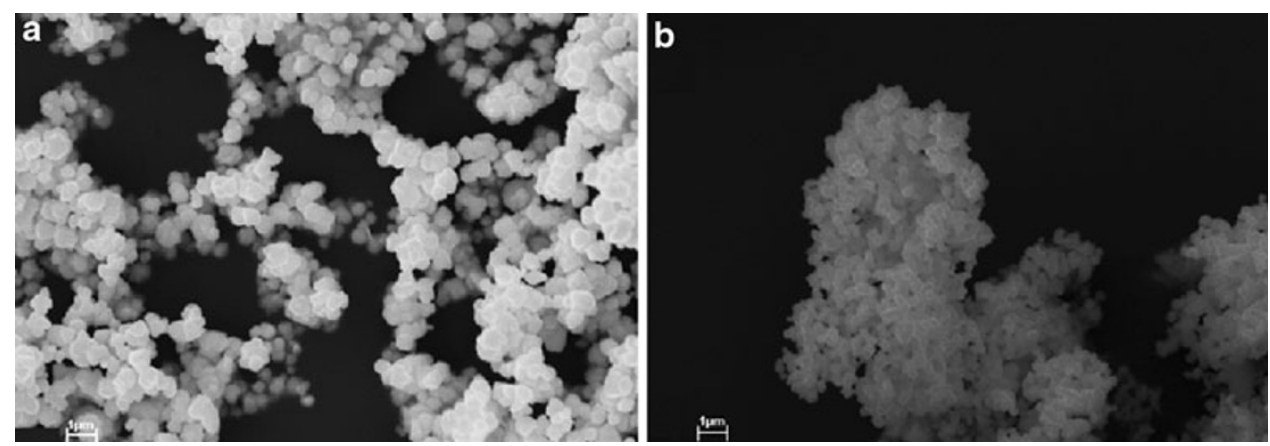

disturbs the charge balance of surfactant, which causes conjugated inverse micelle. This procedure led to production of silver particles with dumbbell-like structures parallel to silver ions reduction inside the inverse micellar templates (Fig. 4).

Effect of using PVP in company with SDBS on the shape and size of the particles under ultrasonic radiation

In order to investigate the self-assembly behavior of SDBS in the presence of PVP, both SDBS and PVP have been used simultaneously in the mentioned reaction condition. Addition of $n$-heptanes to the reaction mixture consisting of surfactants and capping agents resulted in porous surface and dendrite particles (Fig. 5a, b). Figure 5 indicates the probable structures of the surfactant in the presence of PVP and ascorbic acid before and after addition of $n$-heptanes. Similar to silver ions, PVP and ascorbic acid molecules arrange according to their hydrophilic properties in spherical micelles. Diffusion of ascorbic acid within the surfactant molecules decreases their availability to reduce silver ions, therefore retards the reduction process (Arikan and Tunçay 2006). Titration of $n$-heptanes to the reaction mixture under ultrasound radiation could result in electrostatic force balance disruption among organic molecules. According to Suber et al.'s (Suber and Plunkett 2010) report, polymer (polynaphthalene) can organize the silver particle chains in dumbbell-like structures, so it can be deduced that the presence of PVP molecules in contact with the surfactants not only prevents them from detachment, but also arranges them in a directional structure along liner polymer molecules. This rearrangement facilitates the reaction between ascorbic acids and silver ions, thus metallic silver could be instantly formed inside these surfactant templates (Fig. 6).

Sonication continuance resulted in homogenously dispersion of $n$-heptanes in water/surfactant solution and production of stable spherical micelles. Spherical nanoparticles could be produced by Silver ions reduction inside these micellar templates (Fig. 5c), which were recovered from the reaction mixture by centrifuging after $30 \mathrm{~min}$. Centrifuging after 5 days delay rearranged surfactant structures from spherical to cubic forms. Parallel to this evolution, unstable fine nanoparticles tend to crystallize in a cubic structure (Fig. 4d) to reduce surface energy of particles. In a certain proportion of water, silver ions, surfactants, PVP molecules, and $n$-heptanes, longer crystallization time led surfactant molecules to arrange in cubic structures. To reveal the shapes and crystallinity of dendrite particles, transmission electron microscopy (TEM) analysis and selected area electron diffraction (SAED) have been used. The SAED patterns indicated polycrystalline structure of dendrite particles,
Fig. 3 SEM images of synthesized silver particles. a Self-precipitated particles after reduction (sample \#3); b produced particles after adding $n$-heptane, sonicating and then centrifuging (sample \#4)
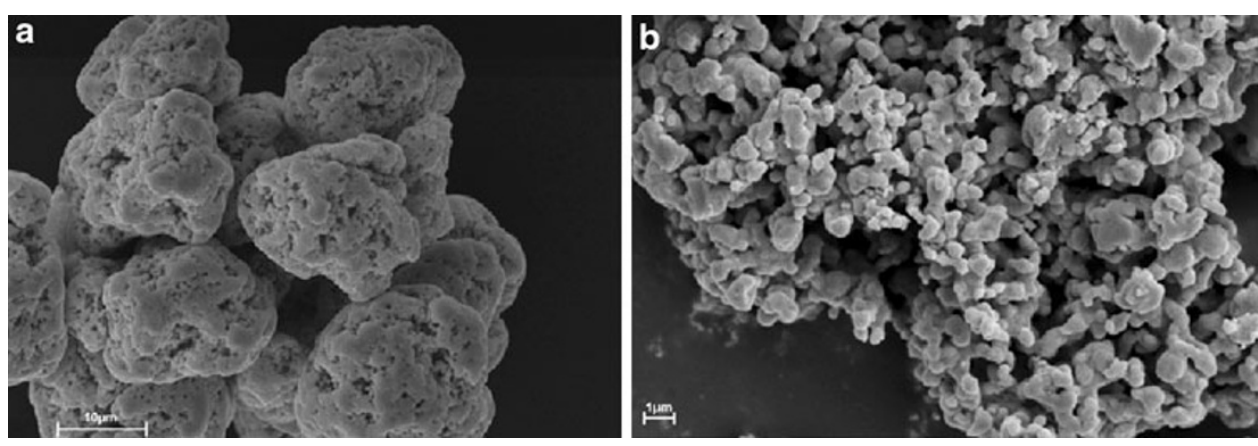

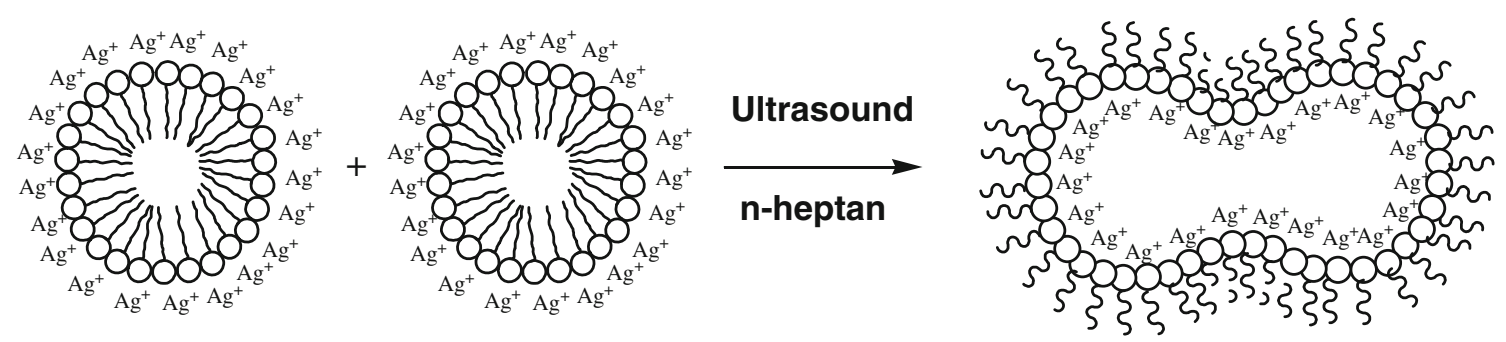

Fig. 4 Schematic structure of synthesized silver particles under ultrasound radiation and organic solvent

Fig. 5 SEM images of synthesized silver particles. a and $\mathbf{b}$ Self-precipitated particles after reduction (sample \#5); c precipitated particles by centrifuging after $30 \mathrm{~min}$ (sample \#6); $\mathbf{d}$ produced cubic particles after 5 days crystallization time (sample \#7)
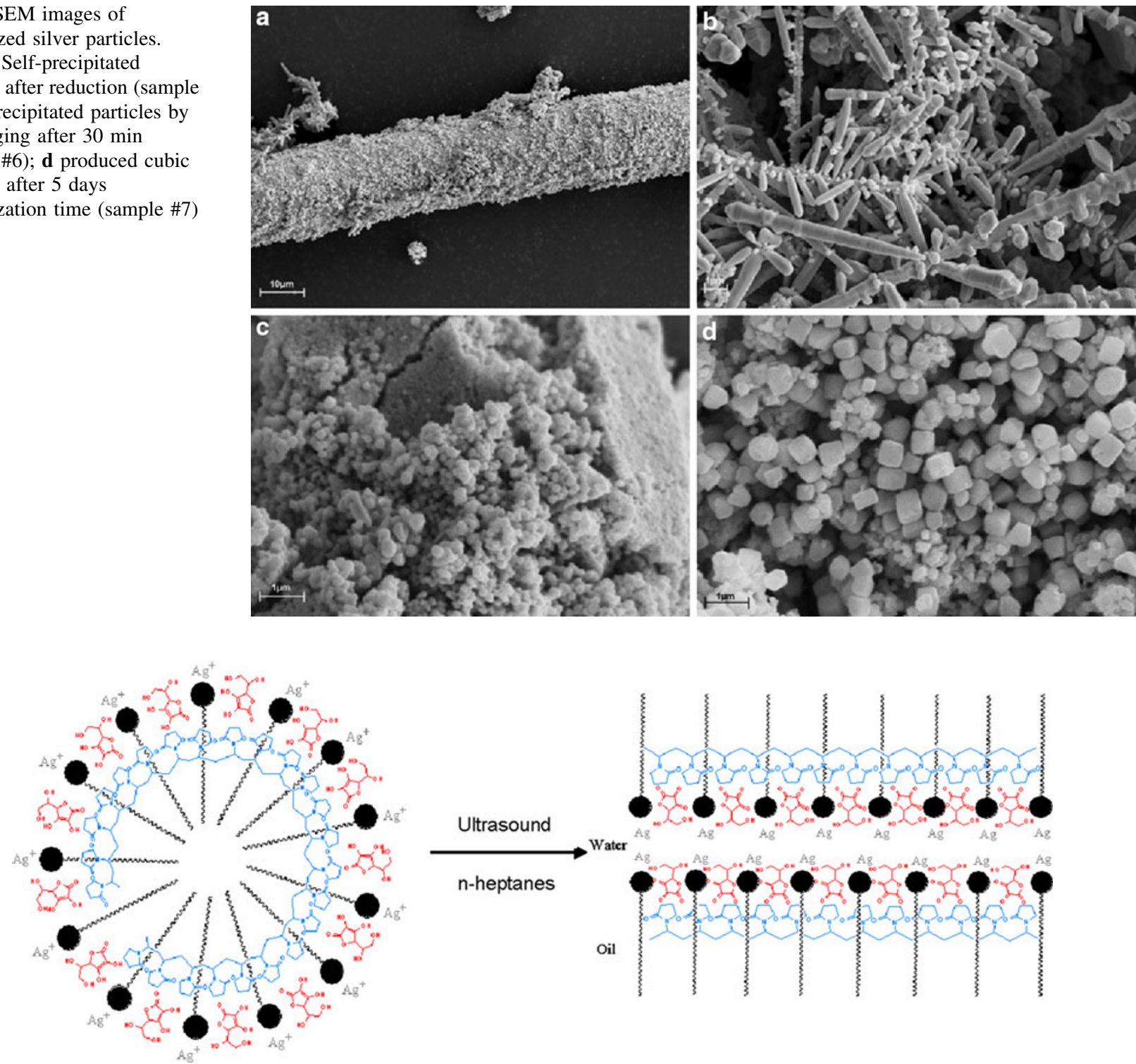

Fig. 6 Schematic structures of ascorbic acid, PVP, surfactant and silver ions with and without the presence of ultrasound radiation and $n$-heptanes

which could be expressed because of silver ions fast reduction. Fast production of silver atoms prevents them from arrangement in single crystal structures. The cloudy-like boundary of dendrite particles in Fig. 7a probably indicates the presence of PVP and SDBS molecules.

Surface porosity of micro-rod and dendrite silver particles have been investigated by using an optical 
Fig. 7 TEM images of synthesized dendrite particles. a, b Dendrite particles (sample \#6); c, d selected area electron diffraction (SAED) of synthesized dendrite particles
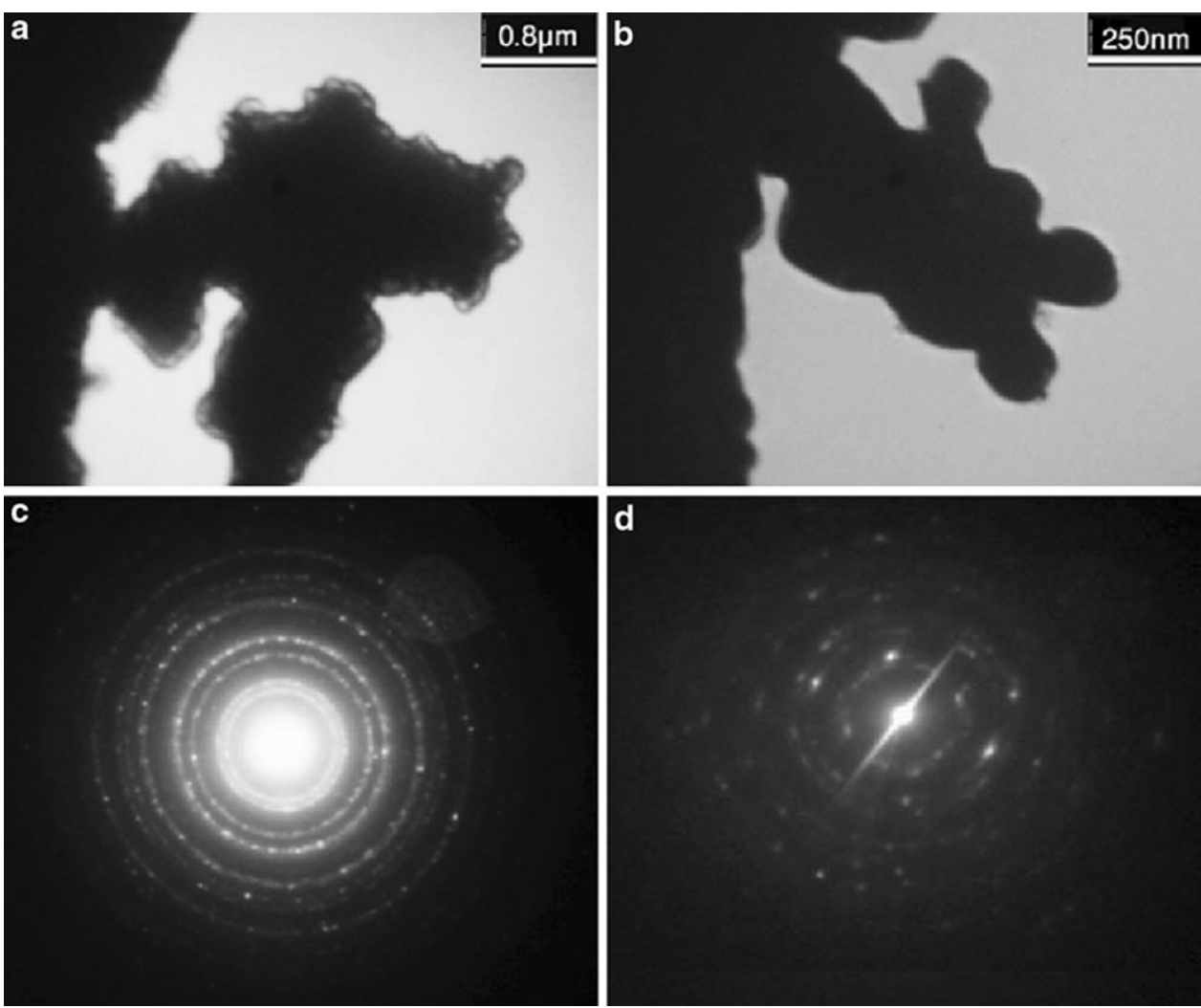

reflectometer device. Results (Fig. 8) revealed that roughness average (RA) for micro-rod surface is $354 \mathrm{~nm}$, and root mean square (RMS) which indicates roughness average precisely, is about $434 \mathrm{~nm}$. Highly porous synthesized particles are useful for catalytic activity (Harunar Rashid and Mandal 2007), heat transfer application (Murtha et al. 2007), antibacterial property (Vimala et al. 2010; Jing et al. 2008), etc. Figure 9 revealed surface roughness of dendrite structures. As it was shown in Fig. 9b, fluctuation of height values is about $2 \mu \mathrm{m}$, which is more than porous micro-rod surface roughness. On the other hand, oblique plot shows branchy structures of surface confirming the dendrite structure of particles.

The surface plasmon property of particles has been investigated by using UV/Visible spectrophotometer (Perkin Elmer Lambada 25). The intensity of the peaks around $430 \mathrm{~nm}$, which is assigned to the plasma resonance of $\mathrm{Ag}$ particles, increased and the peak shifted to the longer wavelength (red shift) showing an increase in the size of the silver nanoparticles (Guoping et al. 2005). Figure 10a shows absorption spectra of final solution compared with initial agents. Absorption at $416 \mathrm{~nm}$ revealed the surface plasmon of silver particles with different shapes in the final solution. Absorption spectra of dendrite structure at $436 \mathrm{~nm}$ correspond to surface plasmon vibration of particles. Broad absorption could be related to the large size and size distribution.

\section{Conclusion}

Pure silver nanoparticles have been synthesized via a wet chemical reaction in the presence of capping agent and surfactant under ultrasound radiation. In summary, size and shape variation of silver particles have been investigated in the presence of PVP, SDBS, and both of them. PVP molecules could reduce the size of synthesized nanoparticles due to an increment in the reduction rate and prevent individual colloidal particles from coalescing with each other. Porous spherical and dumbbell-like structures were produced by surfactant (SDBS) selfassembly in water and water $/ n$-heptanes solutions, respectively. Results show that simultaneous usage of PVP and SDBS could affect the particles morphology by changing the transition structures of surfactant under ultrasound radiation. Presence of PVP molecules in contact with SDBS causes the directional growth of particles, along liner polymer molecules. Homogenous dispersion of $n$-heptanes with and without retardation time causes different morphology (spherical and cubic) related to the surfactant self-arrangement and crystallization 

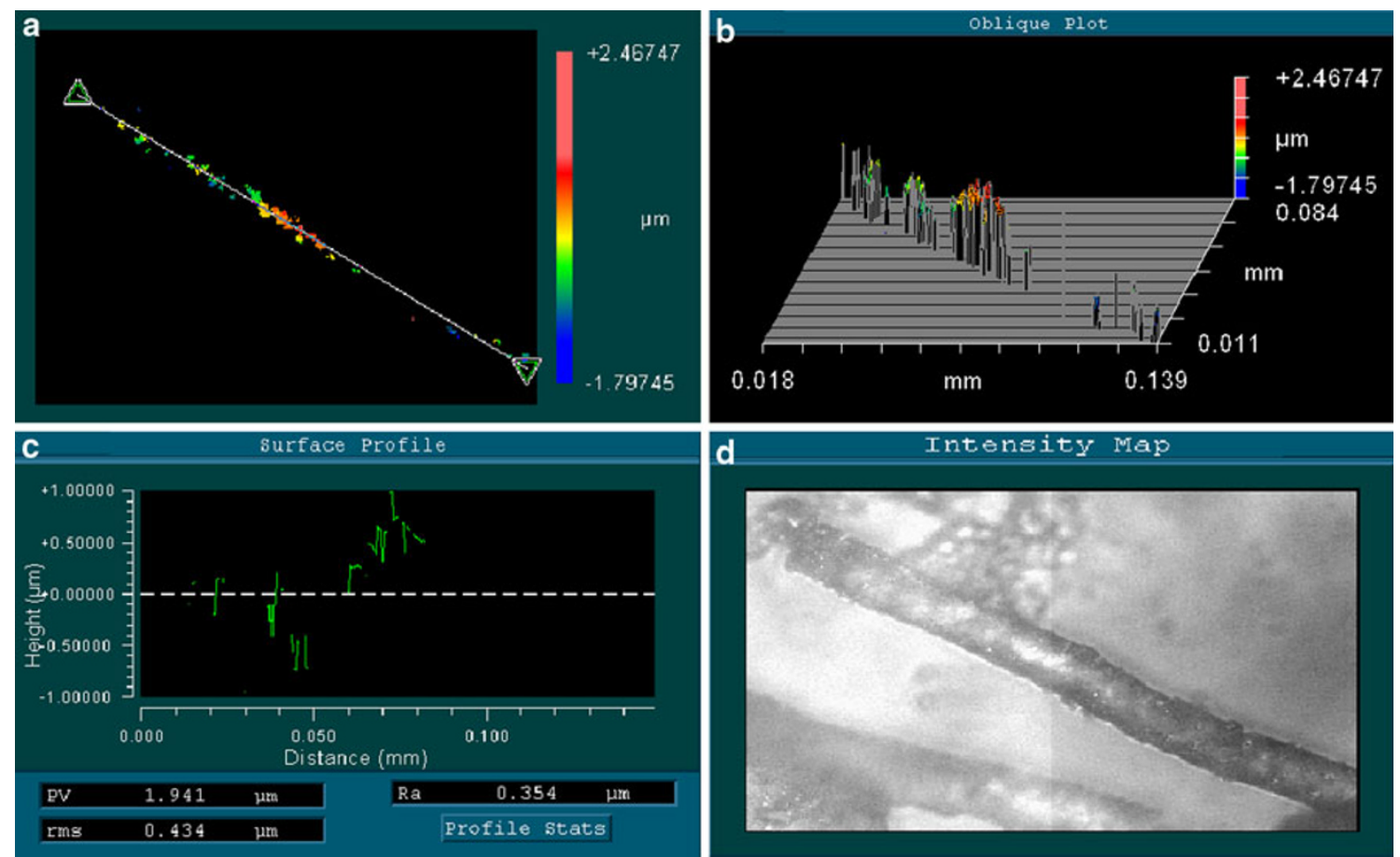

Fig. 8 Refractometer analysis of porous micro-structure
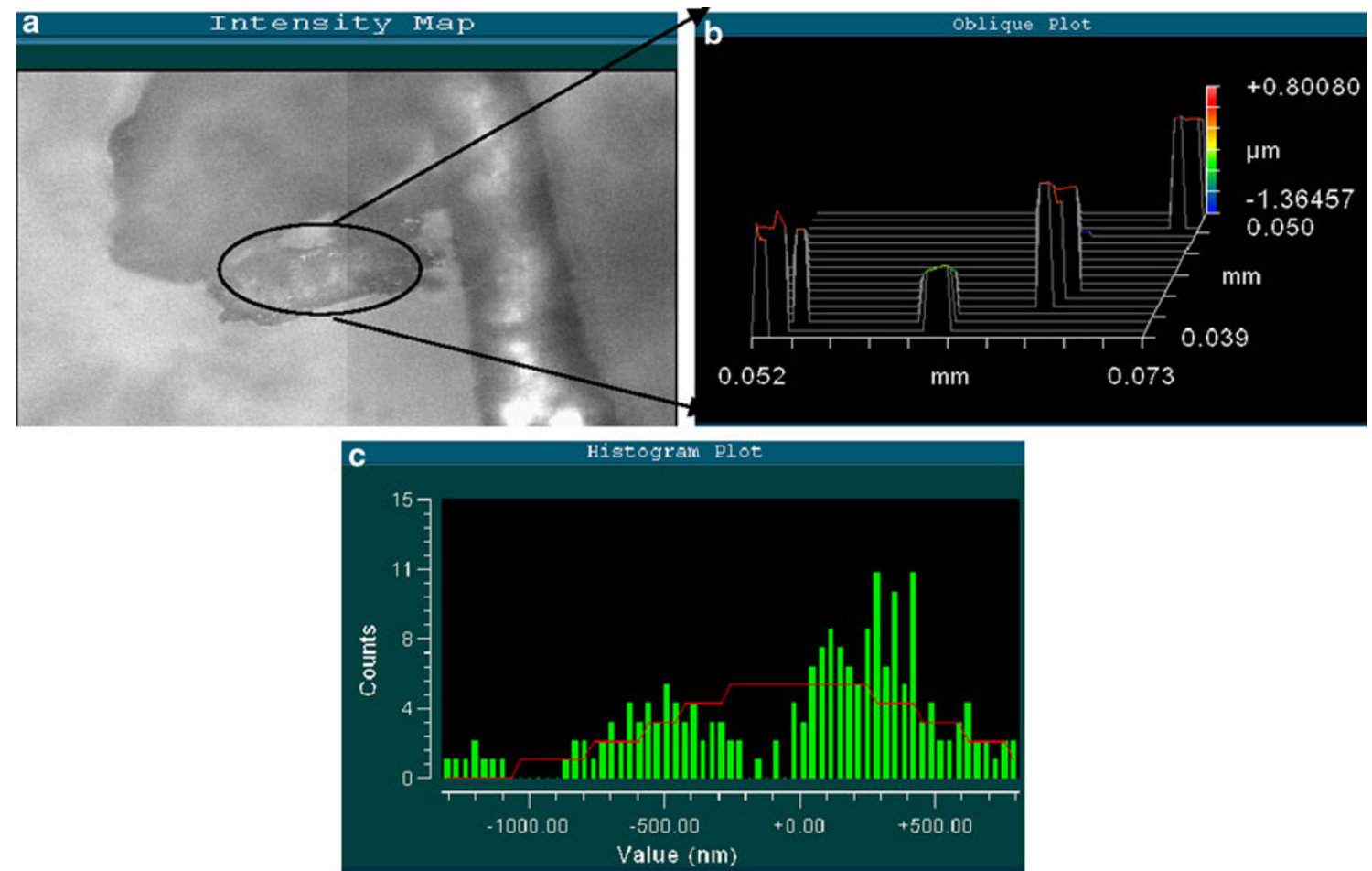

Fig. 9 Refractometer analysis of dendrite structure

time. TEM analysis revealed that fast reduction of silver ions prevents silver atoms from producing regular arrangement, so polycrystalline structures is a result of reaction instead of single-crystalline structures. Optical refractometer revealed surface roughness of porous micro-rod and dendrite structures. In addition, optical spectroscopy has been used to consider the surface plasmon vibration of particles. 

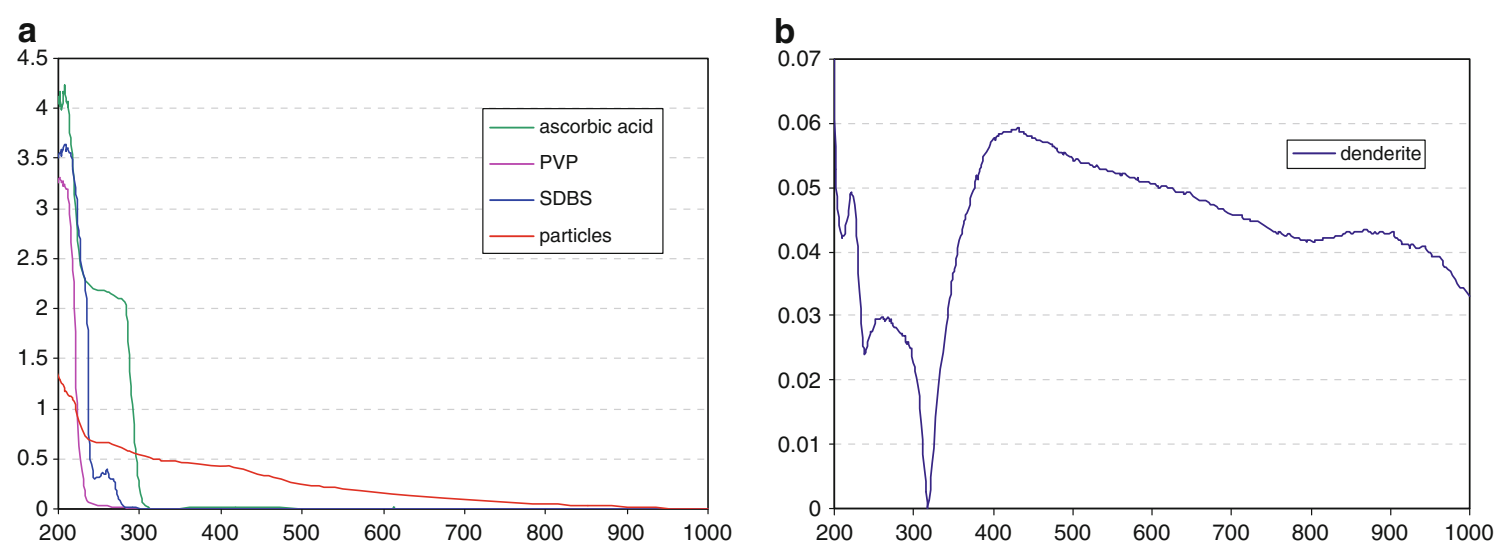

Fig. 10 UV/visible spectrums of a initial reagents and final solution, b dendritic structure

Open Access This article is distributed under the terms of the Creative Commons Attribution License which permits any use, distribution, and reproduction in any medium, provided the original author(s) and source are credited.

\section{References}

Adhyapak PV, Karandikar P, Vijayamohanan K, Athawale AA, Chandwadkar AJ (2004) Synthesis of silver nanowires inside mesoporous MCM-41 host. Mater Lett 58:1168

Ahmadi TS, Wang ZL, Green TC, Henglein A, El-Sayed MA (1996) Shape-controlled synthesis of colloidal platinum nanoparticles. Science 272:1924

Arıkan B, Tunçay M (2006) The effect of SDS micelles on reduction of toluidine blue by ascorbic acid in acid medium. Colloids Surf Physicochem Eng Aspects 273:202

Brito-Silva AM, Gómez LA, De Araújo CB, Galembeck A (2010) Laser ablated silver nanoparticles with nearly the same size in different carrier media. J Nanomater 2010:142897

Cho AY (1999) How molecular beam epitaxy (MBE) began and its projection into the future. J Cryst Growth 202:1

Dan Min K, Park WH, Youk JH, Kwark YJ (2008) Controlling size and distribution of silver nanoparticles generated in inorganic silica nanofibers using poly(vinyl pyrrolidone). Macromol Res $16: 626$

Daniel MC, Astruc D (2004) Gold nanoparticles: assembly, supramolecular chemistry, quantum-size related properties, and applications towards biology, catalysis and nanotechnology. Chem Rev 104:293

Ding X, Xu R, Liu H, Shi W, Liu S, Li Y (2008) Hyperbranched polymer-assisted hydrothermal in situ synthesis of submicrometer silver tubes. Cryst Growth Des 8:2983

Eastoe J, Hollamby MJ, Hudson L (2006) Recent advances in nanoparticle synthesis with reversed micelles. Adv Colloid Interface Sci 5:128

Elechiguerra JL, Burt JL, Morones JR, Camacho-Bragado A, Gao X, Lara HH, Yacaman MJ (2005) Interaction of silver nanoparticles with HIV-1. J Nanobiotechnol 3:6

Gautam A, Singh GP, Ram S (2007) A simple polyol synthesis of silver metal nanopowder of uniform particles. Synthetic Metals 157:5

Guoping L, Yunjun L, Weishang Y, Liang Z, Huimin T (2005) Preparation of dendritic silver nanoparticles by direct chemical reduction. Chem J Internet 7:1
Harunar Rashid Md, Mandal TK (2007) Synthesis and catalytic application of nanostructured silver dendrites. J Phys Chem C 111:16750

Hong BH, Bae SC, Lee SW, Jeong S, Kim KS (2001) Ultrathin single-crystalline silver nanowire arrays formed in an ambient solution phase. Science 294:348

Hu JT, Odom TW, Lieber CM (1999) Chemistry and physics in onedimension: synthesis and properties of nanowires and nanotubes. Acc Chem Res 32:435

Huang T, Murray RW (2001) Visible luminescence of watersoluble monolayer-protected gold clusters. J Phys Chem B 105: 12498

Huang MH, Choudrey A, Yang PD (2000) Ag nanowire formation within mesoporous silica. Chem Commun 1063

Jana NR, Gearheart L, Murphy CJ (2001) Wet chemical synthesis of silver nanorods and nanowires of controllable aspect ratio. Chem Commun 617:618

Jiménez E, Abderrafi K, Martínez-Pastor J, Abargues R (2007) A novel method of nanocrystal fabrication based on laser ablation in liquid environment. Superlattices Microstruct 43:487

Jing H, Yu Z, Li L (2008) Antibacterial properties and corrosion resistance of $\mathrm{Cu}$ and $\mathrm{Ag} / \mathrm{Cu}$ porous materials. J Biomed Mater Res A 87:33

Johnson CJ, Dujardin E, Davis SA, Murphy CJ, Mann S (2002) Electrochemical synthesis of poly(p-xylylenes) (PPXs) and poly(p-phenylenevinylenes) (PPVs) and the study of xylylene (quinodimethane) intermediates: an underrated approach. J Mater Chem 12:1765

Kamat PV (2002) Photophysical, photochemical and photocatalytic aspects of metal nanoparticles. J Phys Chem B 106:7729

Kan C, Cai W, Li C, Zhang L (2005) Optical studies of polyvinylpyrrolidone reduction effect on free and complex metal ions. J Mater Res 20(2):320-324

Kannan Badri N, Natarajan S (2010) Biological synthesis of metal nanoparticles by microbes. Adv Colloid Interface Sci 156:1

Kovalenco MV, Bodnarchuk MI, Lechner RT, Heeser G, Schaffler F, Heiss W (2007) Fatty acid salts as stabilizers in size and shapecontrolled nanocrystal synthesis: the case of inverse spinel iron oxide. J Am Chem Soc 129:6352

Li D, Hong B, Fang W, Guo Y, Lin R (2010) Preparation of welldispersed silver nanoparticles for oil-based nanofluids. Ind Eng Chem Res 49(4):1697

Liu L, Wei T, Guan X, Zi X, He H, Dai H (2009) Size and morphology adjustment of PVP-stabilized silver and gold nanocrystals synthesized by hydrodynamic assisted self-assembly. J Chem C 113:8595 
Mallikarjuna NN, Varma RS (2007) Microwave-assisted shapecontrolled bulk synthesis of noble nanocrystals and their catalytic properties. Cryst Growth Des 7:687

Moghimi-Rad J, Zabihi F, Hadi I, Ebrahimi S, Dallali Isfahani T, Sabbaghzadeh J (2010) Effect of ultrasound radiation on the size and size distribution of synthesized copper particles. J Mater Sci 45:3804

Moon KS, Dong H, Maric R, Pothukuchi S, Hunt A, Li YI, Wong CP (2006) Thermal behavior of silver nanoparticles for lowtemperature interconnect applications. J Electron Mater 34:168

Morones JR, Elechiguerra JL, Camacho A, Holt K, Kouri JB, Ramirez JT, Yacaman MJ (2005) The bactericidal effect of silver nanoparticles. Nanotechnology 16:2346

Murashova IB, Khramov AP, Zotin IV, Zaikov YuP, Zyrjanov VG (2003) Electrocrystallization of fibrous silver deposits from nitrate melts-experiments and modeling. J Min Metallurg 39:137

Murphy CJ (2002) Nanocubes and nanoboxes. Science 298:2139

Murtha BA, Kulkarni AK, Singh J (2007) Effects of heat treatment of highly porous copper/silver systems on thermal conductivity. Int Mech Eng Congr Expo 8:979

Nishino J, Kanno Y (2008) An influence of concentration of polyvinylpyrrolidone on the morphology of silver metal formed from agno3 aqueous solution. J Nanomater 592838

Pileni MP (2003) Role of soft colloidal templates in the control of size and shape of inorganic nanocrystals. Nat Mater 2:145

Qiu T, Wu XL, Mei YF, Chu PK, Siu GG (2005) Self-assembled growth and green emission of gold nanowhiskers. Appl Phys A 81:669

Rosi NL, Mirkin CA (2005) Nanostructures in biodiagnostics. Chem Rev 105:1547

Saez V, Mason TJ (2009) Sonoelectrochemical synthesis of nanoparticles. Molecules 14:4284

Saifoddin N, Wong CW, Nur Yasumira AA (2009) Rapid biosynthesis of silver nanoparticles using culture supernatant of bacteria with microwave irradiation. E-J Chem 6:61

Solano Ruiz E, Berru RS, Flores JO (2010) Synthesis of silver nanoparticles by sonochemical induced reduction application in SERS. J Nano Res 9:77

Suber L, Plunkett WR (2010) Formation mechanism of silver nanoparticle 1D microstructures and their hierarchical assembly into 3D superstructures. Nanoscale 2:128

Suber L, Sondi I, Matijevíc E, Goia DV (2005) Preparation and the mechanisms of formation of silver particles of different morphologies in homogeneous solutions. J Colloid Interface Sci 288:489

Sun Y, Mayers B, Herricks T, Xia Y (2003) Polyol synthesis of uniform silver nanowires: a plausible mechanism and the supporting evidence. Nano Lett 3:955

Sun XY, Xu FQ, Li ZM, Zhang WH (2005) Cyclic voltammetry for the fabrication of high dense silver nanowire arrays with the assistance of AAO template. Mater Chem Phys 90:69
Talebi J, Halladj R, Askari S (2010) Sonochemical synthesis of silver nanoparticles in Y-zeolite substrate. J Mater Sci 45:3318

Tsuji T, Thang DH, Okazaki Y, Nakanishi M, Tsuboi Y, Tsuji M (2008) Preparation of silver nanoparticles by laser ablation in polyvinylpyrrolidone solutions. Appl Surf Sci 254:5224

Vimala K, Mohan YM, Sivudu KS, Varaprasad K, Ravindra S, Reddy NN, Padma Y, Sreedhar B, Raju KM (2010) Fabrication of porous chitosan films impregnated with silver nanoparticles: a facile approach for superior antibacterial application. Colloids Surf B Biointerfaces 76:248

Vinson PK, Bellare JR, Davis HT, Miller WG, Scriven LE (1991) Direct imaging of surfactant micelles, vesicles, discs, and ripple phase structures by cryo-transmission electron microscopy. J Colloid Interface Sci 142:74

Wang X, Naka K, Hideaki I, Sooyun P, Yoshiki C (2002) Synthesis of silver dendritic nanostructures protected by tetrathiafulvalene. Chem Commun 1300:1301

Wang H, Shen Q, Li X, Liu F (2009) Fabrication of copper oxide dumbbell-like architectures via the hydrophobic interaction of adsorbed hydrocarbon chains. Langmuir 25:3152

Wei A (2006) Calixarene-encapsulated nanoparticles: self-assembly into functional nanomaterials. Chem Commun 1581

Wiley B, Sun Y, Mayer B, Xia Y (2005) Shape-controlled synthesis of metal nanostructures: the case of silver. Chem Eur J 11:454

Wu C, Mosher BP, Lyons K, Zeng T (2010) Reducing ability and mechanism for polyvinylpyrrolidone (PVP) in silver nanoparticles synthesis. J Nanosci Nanotechnol 10:2342

Yonezawa Y, Kometani N, Sakaue T, Yano A (2005) Photoreduction of silver ions in a colloidal titanium dioxide suspension. J Photochem Photobiol Chem 171:1

Zhang S (2003) Fabrication of novel biomaterials through molecular self-assembly. Nat Biotechnol 21:1171

Zhang JZ, Wang Z-L, Lio J, Chen Sh, Lio G-Y (2004) Self-assembled nanostructure. Kluwer

Zhang L, Ai Z, Jia F, Liu L, Hu X, Yu JC (2006) Controlled hydrothermal synthesis and growth mechanism of various nanostructured films of copper and silver tellurides. Chem Eur J 12:4185

Zhao XG, Shi JL, Hu B, Zhang LX, Hua ZL (2004) In situ formation of silver nanoparticles inside pore channels of ordered mesoporous silica. Mater Lett 58:2152

Zhou Y, Yu SH, Wang CY, Li XG, Zhu YR, Chen ZY (1999) A novel ultraviolet irradiation photo-reduction technique for preparation of single crystal Ag. Adv Mater 11:850

Zhu YJ, Hu XL (2004) Microwave-assisted polythiol reduction method: a new solid-liquid route to fast preparation of silver nanowires. Mater Lett 58:1517 